\title{
O saber do paci ente chagásico sobre a sua doença: construção compartilhada de um instrumento para a pesquisa e teste de sua aplicabilidade
}

\section{The knowledge of chagasic patients about their disease: collective construction of a research instrument and test of its applicability}

Lucia M aria Ballester-Gil ${ }^{1}$

Eduardo N avarro Stotz ${ }^{2}$

Alejandro $\mathrm{M}$ arcel $\mathrm{H}$ asslocher-M oreno ${ }^{3}$

Belarmino Alves de Azevedo ${ }^{4}$

Tania Cremonini de Araújo-Jorge ${ }^{1}$

${ }^{1}$ Laboratório de Biologia Celular - Setor del novações Terapêuticas eEducacionais, Instituto Oswaldo Cruz, Fundação Oswaldo Cruz. Av. Brasil 4365, M anguinhos. 21040-900 Rio deJaneiro RJ. lucia@ioc.fiocruz.br ${ }^{2}$ Departamento de Endemias Samuel Pessoa, Escola Nacional deSaúdePública Sérgio Arouca, Fundação Oswaldo Cruz.

${ }^{3}$ Centro de Referência em doença de Chagas, Instituto de Pesquisa Clínica Evandro Chagas, Fundação O swaldo Cruz.

${ }^{4}$ Setor de Psicologia M édica, Instituto de Pesquisa Clínica Evandro Chagas, Fundação Oswaldo Cruz.
Abstract This article describes the collective construction of a research instrument (interview guideline) for investigating the knowledge of chagasic patients atten ded at the Chagas D isease R eference $\mathrm{Center}$ of the $\mathrm{O}$ swaldo Cruz Foundation. A multi-professional team worked sequentially on six versions of the guideline for semi-structured interviews. The instrument aims collecting data for a qualitative approach to concepts and perceptions of the patients from the perspective of the human relationships in the context of life and health. It detects the individual experiences re garding thediseasing process, the knowledgeabout the disease (and the infection), the emotions, reactions, and affections. Some theoretical aspects were discussed based on sociological and anthropological practices used in public health actions. We performed a complete interview with a patient for testing and adjusting the instrument. The interview guideline was tested and showed to be a suitable instrument for investigating the knowledge of chagasic patients, covering many subjective and cognitive aspects. This knowledge can be a useful contribution to the development of strategies, actions and information material aimed at improving and humanizing the care delivered to Chagas disease patients.

Key words Knowledge, Perceptions, Patients, Chagas disease, Interview guideline
Resumo Relatamos a experiência de construção compartilhada deum instrumento de pesquisa (roteiro de entrevista) para investigar os saberes de pacientes chagásicos atendidos na Fundação Oswaldo Cruz. Profissionais de diferentes setores de pesquisa da instituição participaram da expe riência de desenvolvimento do roteiro de entrevista semi-estruturada, passando por seis versões. 0 roteiro elaborado objetiva recol her dados para uma abordagem qualitativa das concepções e percepções de pacientes sob uma perspectiva de relações humanas no contexto de saúdee vida, identificando as vivências do processo de adoecer, seus conhe cimentos sobre a doença (e a infecção), suas emoções, reações e afetos. Pontuamos aspectos teóricos oriundos da reflexão sobreas práticas sociológica e antropológica em ações em saúde coletiva. Subme tido a teste para ajustes, o roteiro de entrevista confirmou-se adequado para o estudo de saberes de pacientes chagásicos, captando diversos aspectos subjetivos e cognitivos que podem ser úteis para a formulação de estratégias, ações e materiais informativos que contribuam para a melhoria e humanização da atenção ao paci ente chagásico. Palavras-chave Concepções, Saberes, D oença de Chagas, Roteiro de entrevista 
Introdução

O tema de "concepções e percepções sociais" tem sido tratado na literatura em pesquisa social em saúde ${ }^{1}$, evidenciando aspectos subjetivos da vivência de pacientes em doenças crônicas através de instrumentos padronizados ${ }^{2}$ ou por meio de entrevistas abertas ${ }^{3}$. No entanto, a metodologia qualitativa ${ }^{4,5}$, interessante para essa abordagem, carece deinstrumentos com amplitude para analisar as concepções e percepções de pacientes sob uma perspectiva de relações humanas no contexto de saúde e vida. Como captar vivências do processo de adoecer num processo que sofre a ação de diferentes sujeitos nas equipes multiprofissionais de atenção à saúde? Quais são os aspectos da comunicação, informação, emoção, razão e afetos em cena nessas relações?

0 objetivo deste trabal ho foi construir e testar um roteiro deentrevista para levantar as concepções, saberes e percepções de pacientes com doença de Chagas, levando em consideração o seu processo de adoecimento e enfrentamento da doença. Para tal, compusemos uma equipe multidisciplinar biopsicossocial (os autores) e transformamos gradualmenteum "questionário" num rotei ro de entrevista que, na perspectiva de uma atenção integrada ao paciente, pudesse nos fornecer elementos para ações de apoio psicossocial e educativas levando em conta seus sabe res e necessidades ${ }^{6}$.

A doença de Chagas, causada pelo Trypanosoma cruzi, é dentre as chamadas grandes endemias negligenciadas ${ }^{7}$ a que maior impacto de morbi-mortalidade produz na América Latina ${ }^{8}$, ondeacomete 16 milhões depessoas. Inserida num novo contexto de globalização ${ }^{9}$, pelas profundas transformações sociais derivadas do fluxo migratório campo-cidade e entre países, seu controle e tratamento são hoje prioridades da Organização Mundial deSaúde ${ }^{10}$. Asformas principais detransmissão do T. cruzi aos humanos são a vetorial ea transplacentária-congênita, da mãe infectada para o recém nascido ${ }^{11}$. No Brasil, há cerca de 5 miIhões de infectados em fase crônica ${ }^{12}$. Eles vivem na expectativa de poderem vir a desenvolver uma das formas clínicas graves da doença, a incerteza quanto à capacidade para o trabalho e muitas vezes desconhecem o processo da infecção. Com elevado custo ${ }^{11}$, a doença de Chagas é um sério problema social, econômico epolítico queafeta a população oriunda de extratos mais pobres $8,9,13,14$ erequer um enfrentamento integral, multiprofissional, com ações intersetoriais.

H istoricamenteno Brasil, a educação em saú- de referente às grandes endemias consiste em ações de tipo vertical, intervencionista e temporário ${ }^{15}$. Há mais de três décadas, a questão da educação já se apresenta como crucial|16-18 e necessária ${ }^{19}$, inclusive em áreas onde a infestação de casas pelo inseto vetor já foi controlada ${ }^{20}$. Como para outras doenças crônicas, as abordagens educativas aplicadas à doença de Chagas apresentam três componentes ${ }^{21}$ : (1) a prevenção primária, com educação visando à prevenção da infecção em áreas endêmicas com transmissão ativa e promoção de conscientização para vigilância epidemiológica onde a transmissão vetorial já tiver sido controlada; (2) a prevenção secundária, com educação de pessoas infectadas, visando ao seu engajamento pleno e ativo no acompanhamento da evolução de seu quadro e desenvolvimento em sua terapêutica, para prevenir a mortalidade e o agravamento da doença; e(3) a prevenção terciária, com ações e estratégias de limitação da incapacidade dos pacientes e de reintegração do indivíduo na sociedade.

Poucos trabalhos tratam de educação para prevenção secundária eterciária de pacientescom doenças negligenciadas ${ }^{22-26}$ e há necessidade de novos instrumentos para ações educativas, construídas com base num conhecimento da cultura e do nível educacional dos sujeitos que se quer atingir, bem como de avaliação de seu impacto. Um estudo de impressos divulgados em ambiente hospitalar ${ }^{6}$ mostrou quetendem a refletir mais a experiência profissional do atendimento, a partir de seu estereótipo sobre a clientela, suas carências e necessidades. 0 resultado é quase sempre uma visão distorcida dessa clientela, subjugada pela falta ou escassez de recursos materiais, culturais e simbólicos. 0 conhecimento é repassado ao paciente seguindo o modelo informativo, restrito ao diagnóstico e terapia ${ }^{27}$.

O campo da Educação em Saúde vem formulando críticas ealternativas de ação ao modelo de prevenção tradicional28. Ao compartilhar e explorar crenças e valores, e as suas implicações práticas, é possível que os indivíduos reformulem as informações que tinham antes, assumindo, eventualmente, uma atuação na sociedade, disseminando os conhecimentos desenvolvidos em prol da troca de experiências interpessoai ${ }^{28}$. Um dos objetivos da educação em saúde é o de facilitar a autonomia, isto é, o poder de decisão dos indivíduos sobre suas vidas ou o máximo controle sobre seu próprio destino, que inclui, necessariamente, uma dimensão cultural e ética $^{29}$. O processo de produção da saúde/doença/ intervenção passa a ser entendido no contexto de 
seus determinantes sociohistóricos, como também do autoreconhecimento e potencialização das capacidades individuais e grupais. A doença de Chagas humana ${ }^{8,9,14}$, numa visão integradora, transcende em muito o fato biológico da presença do parasita no indivíduo infectado, e se apresenta com elementos e fatores de risco políticos e sociais marcantes, como a habitação, os fatores de produção, o sistema de saúde, a educação, as ligações políticas einternacionais. Estudos antropológicos ganham espaço ${ }^{3,30}$ e apontam problemas não abordados nas vertentes biomédicas clássicas. Estudos clínicos mostram necessidades de campanhas de esclarecimento e informação ao paciente chagásico sobre riscos diversos $\mathrm{s}^{31,32}$. Torna-se imperativo investigar de forma holística a realidade do paci ente chagásico enquanto cidadão, em um contexto biopsicossocial e cultural. Não se trata de uma transposição de campos, porém da necessidade de um esforço de reconstrução do enfoque médico a partir da dimensão humana, com o resgate do apoio psicológico, importante para o paciente chagási$\mathrm{CO}^{2,3,3,9,12,13,33,34}$. A consciência de portar uma doença grave que está muitas vezes relacionada à morte súbita traz ao chagásico grande angústia3. Em alguns relatos ${ }^{33}$, esse aspecto torna-se mais dramático, quando o indivíduo descobre a infecção ao realizar exame para doação de sangue: para um ato de solidariedade, ele recebe uma notícia opressora eexcludente que o rotula como vítima. Em geral, os pacientes chagásicos sabem muito pouco sobre a doença e, se sabem algo, são mínimas a possi bilidade de definir a real direção de sua vida, suas condições de saúde e sobrevivência ${ }^{33}$. A contribuição da antropologia torna-se aqui fundamental, indicando a necessidade de humanização e al gumas reflexões teórico-filosóficas ${ }^{3,33}$. Os profissionais de saúde apresentam uma percepção específica, enão necessariamente próxima à do paciente, daquilo que é relevante e problemático, do que causa ou evita um problema, e do tipo de ação que esse proble ma requer. Essa visão é determinada pelo seu conjunto de conhecimentos biomédicos. Já para os pacientes, indivíduos leigos de uma comunidadeou grupo, esta percepção é determinada por redes de símbolos que articulam conceitos biomédicos eculturais, e determinam formas características de pensar e de agir em face de um problema de saúde $e^{3,30,35}$. E, obviamente, os profissionais de saúde, quando se relacionam com pessoas ditas "leigas", não são professores a escrever em um livro de páginas em branco.

Nosso trabalho encontra-se ancorado nos pressupostos teóricos deFreire ${ }^{36}$, Briceño-Leon ${ }^{37}$, Kübler-Ross ${ }^{38}$, Valla ${ }^{39,40}$ e Stotz ${ }^{35}$ pelo vínculo e compromisso com a emancipação das classes populares, em defesa da vida. A aproximação com o pacientedeveestar pautada na vivência esubjetividade, que exigea possibilidade derel ações dialógicas esocialização dos saberes, dentro das possibilidades e limites dos sujeitos em cada momento.

Segundo Briceño-Leon ${ }^{8,13,37}$, a interpretação da saúde ocorrecomo um momento de uma realidade social. Portanto, inclui condições de vida dignas e saudáveis, de acordo com os conhecimentos que hoje usufruímos nas condições históricas em que vivemos. No caso da doença de Chagas, o acompanhamento do indivíduo assintomático, que sabe ter a infecção, mas não sabe quando ou se a doença vai se manifestar, é um desafio adicional para o manejo clínico, que lida mais freqüentemente com pacientes na formas cardíaca ou digestiva, ambas com grande impacto na sua vida ${ }^{11}$. Os estudos de KüblerRoss $^{38}$ sobre pacientes crônicos contribuíram para a compreensão de que, ao fornecer ao paciente informação clara quanto ao seu diagnóstico, o profissional de saúde deve deixar portas abertas à esperança, sobretudo, quanto ao uso de novos medicamentos, novos tratamentos, novas tecnologias e pesquisas. A aproximação médico-pacienteéfundamental para situaçõesem que sua doença crônica exigirá mais atenção e persistência no tratamento, buscando encorajálo a retornar para outras consultas. 0 conforto, verbal ou não, senão contribuir diretamentepara prolongar a vida, ao menos poderá criar possibilidades de acolhimento. 0 essencial é comunicar ao paciente que não deverá abandonar o acompanhamento ou tratamento por causa de um diagnóstico grave. $\mathrm{N}$ esse campo, tomaremos como pressuposto teórico as teses de Freire ${ }^{36}$ de que "a educação deve ampliar enão restringir", e de que "é necessário darmos oportunidade para que os sujeitos sejam eles mesmos; caso contrário, domesticamos, o que significa a negação da educação". Ao possibilitar o domínio dos conhecimentos culturais e científicos, a educação socializa o saber sistematizado e desenvolve capacidades cognitivas eoperativas dos indivíduos para a atuação no trabal ho ea luta pela conquista dos direitos de cidadania. Correntes de pensamento pautadas em teorias educacionais que preconizam a participação, de cunho construtivista, e a orientação libertadora, tendo como base as relações dialógicas, devem resultar na ampliação da consciência e na aquisição de habilidades. Tratase dos elementos essenciais para a formação de 
cidadãos capazes de uma participação efetiva na vida social ${ }^{36}$.

\section{M etodologia}

U samos a abordagem qualitativa ${ }^{4,5,41}$, na qual 0 pesquisador tem consciência crítica sobre possibilidades de interferências, que podem comprometer a qualidade dos dados em razão de sua subjetividade e do caráter do fenômeno investigado. 0 material primordial é a palavra que expressa a fala cotidiana, seja nas relações afetivas e técnicas, seja nos discursos intelectuais, burocráticos e políticos. A abordagem qualitativa aproxima sujei to e objeto ${ }^{4,5}$, uma vez que ambos são da mesma natureza: ela se desenvolve com empatia aos motivos, às intenções, aos projetos dos atores a partir dos quais as ações, as estruturas e as relações se tornam significativas. Como não se chega ao contexto da vida separadamente da relação direta e indireta com o pesquisado, pois esse contexto não é construído abstratamente como uma "síntese" de dados baseada numa hipótese prévia a qualquer contato com o pesquisado, é no campo da subjetividade e do simbolismo que se afirma a abordagem qualitativa.

Com base estudos anteriores ${ }^{42-44}$, preparamos um instrumento para levantamento das concepções dos pacientes, um roteiro de entrevista com modelo semi-estruturado, com perguntas abertas e objetivas para uma conversa gravada. Seguimos a proposta de Queiroz ${ }^{45}$, na qual o diálogo entre pesquisador e 0 entrevistado tem por objetivo a coleta deinformações precisas sobre determinado problema, por meio de perguntas e respostas efetuadas de manei ra direta, tanto quanto possível; o pesquisador define sempre de antemão, em detal he, o que está procurando. A entrevista com roteiro oferece certo grau de liberdade, quando disponibiliza o discurso do entrevistado sobre seus problemas todas às vezes que o pesquisador percebe uma divagação para rumos totalmente diversos; tratase, pois, de dosar as intervenções. M as também nestecaso o pesquisador segue um caminho predeterminado, e suas intervenções são no sentido de conduzir ao caminho no qual a investigação está concentrada. Atualmente, estetipo de entrevista com roteiro tem sido preferido ao diálogo de entrevista aberta $^{3}$, pois apresenta a vantagem de colher dados desejados com maior espontaneidade por parte do entrevistado. Está inspirada no modelo dos "sistemas de signos, significados e ações" 30 quando se investiga aspectos so- ciais, culturaise experiências queintervêm na identificação do que é problemático, bem como na elaboração de estratégias para a solução dos problemas. E adota a perspectiva de Bourdieu ${ }^{46}$, que nos alerta que o pesquisador deve procurar se colocar no "lugar" do pesquisado.

A análise dos dados é a etapa final para articular os dados e os referenciais teóricos respondendo às questões da pesquisa com base em seus objetivos $s^{4,5}$. Assim se revelam as relações entre 0 concreto e o abstrato, o geral e o particular, a teoria e a prática. 0 trabalho de conhecimento social tem que atingir três dimensões ${ }^{47}$ : a simbólica, a histórica e a concreta. A dimensão simbólica contempla os significados dos sujeitos, a histórica privilegia o tempo consolidado do espaço real e analítico, e a concreta refere-se às estruturas e aos atores sociais em relação. Para analisar os dados, após as entrevistas, transcrevemos as fitas, realizamos uma primeira leitura do material, organizamos os relatos, revimos objetivos equestões teóricas discutidas no estudo. Terminada esta etapa, mapeamos os discursos, segundo os temas emergentes (sempre guiados pelos objetivos da pesquisa) para fazer a análise de conteúdo ${ }^{4}$.

\section{Resultados}

Descrição do processo de construção compartilhada do roteiro de entrevista

0 processo de transformação do roteiro não ocorreu de forma linear, mas de modo dinâmico. O ito encontros foram registrados, desenvolvendo as seguintes etapas formadoras do roteiro: 1) elaboração da lista de perguntas, baseadas no roteiro de prontuário do IPEC e outras; 2) numeração das questões totalizando 21 perguntas preliminares; 3) classificação das perguntas por blocos de dados pessoais, aspectos cognitivos, socioeconômicos e emocionais; 4) adequação da redação das perguntas à linguagem coloquial; 5) reorganização do roteiro priorizando o aspecto emocional, buscando ampliar a possibilidade de registro da reação do paciente ao diagnóstico, bem como o enfrentamento do problema; 6) inserção de três momentos na entrevista: preocupação com o acolhimento (apresentação), 0 desenrolar (perguntas), e a despedida, situando então expectativa de outros encontros; 7) definição de inserção do gravador para registro da entrevista, sem registros escritos durante as conversas; escolha do momento da assinatura do Termo de Consentimento Livre e Esclarecido 
(TCLE): após a apresentação e explicação do projeto, quando da informação dos dados pessoais; 8) definição de uma possibilidade de retorno do paciente para saber dos resultados da pesquisa; 9) definição da proposta do uso deum instrumento de lembrança para o paciente, um impresso sobre a pesquisa e seus resultados; 10) definição de questões operacionais: a participação do paciente seria opcional, após uma consulta médica; 0 anonimato seria garantido com identificação apenas pela sigla formada por pelas iniciais de seu nome. Cada entrevista deveria se desenvolver por 40 minutos, mas com a flexibilidadeque pudesse atender ao interesse do paciente até sua finalização. O TCLE, explicado e lido para o paciente, introduzia: "Vocêestá sendo convidado para participar de uma pesquisa para esclarecer quais são os saberes e percepções dos pacientes portadores de doença de Chagas sobre a sua doença. Com base nesses resultados, pretendemos colaborar com a equipe do IPEC na organização de uma sala de convívio para pacientes, bem como fornecer dados para outras pesquisas em benefício da melhoria da qualidade dos serviços hospitalares prestados". Após a assinatura do TCLE, não haveria necessidade de qualquer registro escrito: com o roteiro e o gravador, o entrevistador se concentraria em deixar o paciente à vontade para as respostas, e organiza posteriormente os dados gravados segundo as categorias pesquisadas. 0 projeto completo prevê estudos com pacientes em primeira consulta, com pacientes internados e com pacientes com mais de um ano de submissão a tratamento etiológico ou sindrômico. Dois instrumentos de intervenção (acessórios) foram também preparados: um ál bum de imagens fotográficas relativas à doença de Chagas e um quadro de insetos para identificação de vetores.

No decorrer dos encontros, foram construídas seis versões do roteiro, destacando-se a última por ter uma preocupação maior com 0 acoIhimento ao paciente antes do início da entrevista (ver Anexo). Posteriormente, uma sétima versão, revisada pelo Comitê de Ética em Pesquisa, foi testada, e uma oitava versão é a que consideramos como final, a ser adotada em estudos posteriores. As 50 perguntas propostas foram distribuídas em quatro blocos: (1) o acolhimento, quando o entrevistador se apresenta, apresenta a pesquisa, colhee/ou confirma sobre dados pessoais e procura criar um ambiente de confiança para que ele/ela possa falar etambém perguntar; (2) a coleta principal de dados, com perguntas sobre: (i) sua saúde, (ii) sua reação ao diagnósti- co, (iii) seu sentimento em relação à doença; (iv) as relações da doença com familiares e conhecidos, (v) as expectativas e temores, (vi) suas queixas e problemas físicos, (vii) suas percepções sobre discriminação ou prejuízos, (viii) seus conhecimentos sobre o que se passa com ele durante a doença; (3) a despedida, com perguntas sobre sua relação com o hospital e seus diversos serviços, e sobre a relação com a ciência e a produção de conhecimento; e (4) a confirmação de dados socioeconômicos. 0 Anexo apresenta na íntegra o roteiro de entrevista desenvolvido.

\section{Roteiro modificado após análise do}

Comitê de Ética em Pesquisa e testado

Submetido ao Comitê de Ética em Pesquisa do IPEC, o roteiro construído pela equipe foi considerado extenso e, como requisito para aprovação, foi modificado para apenas dois blocos: (1) acolhimento e coleta de dados pessoais e socioeconômicos, com 27 itens, e (2) percepções e saberes do paciente sobre sua doença e atendimento, com dezesseis itens. As intervenções educativas previstas também foram adiadas para um momento posterior ao estudo. 0 projeto foi aprovado em junho de 2005 (protocolo 0054.0.009.011-05) e, por motivos operacionais, a versão modificada foi testada experimentalmente em dezembro de 2007, com paciente de primeira consulta, para identificação de potenciais ajustes, antes de ser aplicado no estudo com um número maior de indivíduos. Apósa consulta clínica, a entrevistadora foi apresentada à paciente pelo próprio médico, na porta do consultório. A entrevista foi conduzidano setor deabertura de prontuário, gravada e depois integralmente transcrita, com registro do tempo total utilizado. O TCLE foi apresentado e explicado à paciente, sendo assinado no início do trabalho.

Muito generosa e disponível para participar da entrevista, a senhora GM JS, mineira de 66 anos, nos dedicou 40 minutos para a conversa orientada pelo roteiro, cinco usados no primeiro e 35 minutos no segundo bloco de perguntas. Esse tempo foi suficiente para incluir a fala de temas não constantes do roteiro, deinteresse específico do paciente, emoções que geraram silêncios e momentos de choro pelo relato de alguns deseus sofrimentos cotidianos. Ela considerou positiva a oportunidade para falar aberta e francamente sobre o seu problema e, indagada por diversas vezes sobre se queria interromper a entrevista, preferiu continuar.

0 roteiro de en trevista mostrou-se eficaz para 
propiciar o diálogo e as perguntas de acol himento funcionaram adequadamente. A pós a confirmação de nome e idade, perguntamos explicitamente setinha mais al guma dúvida, setinha compreendido o objetivo da pesquisa e se podíamos começar, tendo sua anuência. A paciente nos relatou que era natural de M inas Gerais (em Bom Despacho. A minha família é toda de lá); que é divorciada, que sabia escrever seu nome (leio muito pouco), que morava sozinha no bairro da Ilha do Governador equevivia no Rio deJaneiro há mais de quarenta anos (vim para o Rio muito nova). Quanto ao trabalho erenda, relatou queé aposentada do lar etem renda mensal de um salário mínimo. Questionada sobrese precisa deajuda financeira de outra pessoa, respondeu Sim, masnão peço nada às minhas fillhas. Cada um tem a sua vida. Tenho muitas necessidades. M as como vivo sozinha com um salário mínimo procuro gastar somente o suficiente para viver. M oro na favela e lá é tudo pobreza. Sobre seus dados habitacionais (casa própria ou alugada), respondeu: Eu moro no começo da favela. Lá é posse. Sobre as condições de abastecimento deágua seus comentários foram: a água é nojenta pra caramba. É uma água que vem de uma caixa da comunidade, que é distribuída pro pessoal. Acho que não tem tratamento, não. A caixa éimensa. E pelas pessoas que tomam conta, eu tô querendo comprar aquelas águas de garrafão, já queéeu sozinha. Relatou ter esgoto, coleta de lixo eluz elétrica.

Finalizamos com a pergunta sobre dificuldades físicas para trabalhar e sobre o recebimento de benefícios. A paciente respondeu: Sinto uma fraqueza igual a quando se volta do hospital. Falta dear, cansaço, dor nas pernas e o meu coração tem batido rápi do demais. Estou muito triste, penso que vou morrer todo tempo. Depois que recebi o meu resultado, minha vida mudou. Não quero morrer. Bem, eu perguntei para o médico e ele disse que é preciso fazer exames, depende do caso e, no meu, pelo estado, vou ter que colocar um marca-passo. Eu sei dos efeitos do marca-passo na pessoa, émuito ruim ea cirurgia écomplicada. A pessoa fica com o coração fraco. Não conhecia possíveis benefíciose direitos, não tinha cartão do SUS, não tinha plano de saúde privado, não participava de nenhum grupo de apoio à terceira idade e nem do programa de acompanhamento a hipertensos.

Confirmamos que essa última pergunta realmente deveriaser ao final do primeiro bloco, pois introduz as questões da sensação do pacientecom o diagnóstico e a doença, possibilitando uma articulação com as perguntas do segundo bloco. Aqui houve grande riqueza de dados e algumas perguntas tiveram queser reformuladas para que a paciente compreendesse 0 que se queria saber. Descreveremos tanto as alterações feitas nas perguntas, como a respostas obtidas.

As três primeiras perguntas 1) "Como a senhora ficou sabendo que é portadora da doença deChagas?; 2) "De que forma conseguiu 0 atendimento no IPEC?"; 3) "A senhora selembraquem Ihe forneceu o resultado dos exames? 0 que a pessoa Ihe disse na ocasião?" ) tiveram que ser reformuladas para: 1) "Como a senhora chegou até o hospital para fazer a consulta?" R: Eu peguei um encaminhamento do hospital público. Aí eu já sabia que aqui se estuda muitas doenças e eu vim; 2) "A senhora recebeu o resultado hoje?" R: Eu já tinha recebido. Ele me deu e marcou a consulta pra hoje. No exame que foi feito aqui, está parecendo doença de Chagas. N os outros exames eu fiz um eco, um eletro e aí o médico tá com dúvida. É que estou com um batimento meio assim estranho [pausa, em silêncio]. Eu tenho sentido muita coisa. E o médico acha que não é só das Chagas. Ele pediu estes exames todinhos para tirar as dúvidas. 0 médico foi atencioso comigo e muito educado.

A pergunta 4 ( "A senhora recebeu al gum tipo de informação sobre a sua doença durante as consultas?") foi adaptada para: 4) "A senhora recebeu algum material de informação aqui no hospital?" R: Não. Eu teria vontade de receber assim uma orientação, assim uma leitura que é pra mim saber o que traz essa doença. 0 que pode e 0 que não podena doença de Chagas.

As perguntas 5 e 6 , sobre aspectos de seus saberes sobre a doença - 5)" Por que a senhora acha que adoeceu?"; 6) "O que a senhora sabe sobre a sua doença?") foram adaptadas para: 5) "A senhora sabe o que é doença de Chagas?" R: Sei é do barbeiro. 0 coração fica fraco e grande. Sei. Eu tenho parentes que têm. Eu tenho duas irmãs que têm. M eus pais morreram com problema de coração mais duas irmãs. É só isso que eu sei; 6) "O que mais a senhora sabe sobre doença de Chagas se precisasse dar uma informação para outra pessoa?" R: A informação que tenho das Chagas e que ela não tem cura. A informação queeu ouvi é essa quenão tem cura. Ela pode alojar no coração e pode também no intestino. Eu tenho muita prisão de ventre também, demais. Quer dizer queéa única coisa que eu fiquei sabendo. M ais coisa assim, eu não sei outras causas que pode surgir, não.

As perguntas 7 e 8, sobre a sua saúde, dores, sensações, reações ao diagnóstico e à sua condição de paciente com doença de Chagas - 7) "Como está a sua saúde ultimamente? Sente al- 
guma dor?"; 8) "De que forma a senhora reage a esta doença?" -, foram as que possi bilitaram maior expressão da paciente frente à problemática da doença: 7) "Nos últimos tempos, como está a sua saúde?" R: M eu coração está diferente. A minha pressão está alta. Tenho dificuldade para engolir e tenho dor aqui perto do estômago. Parece uma hérnia.Tenho fraqueza, eu sinto fraqueza. Quando eu como, eu me sinto mais fraca. Quando eu como. Eu tenho uma hérnia no esôfago. U ma hérnia umbilical. Tenho úlcera varicose. Eu tenho osteoporose, artrose. Eu sou toda complicada. Onde estou mais nervosa é por causa disso. Se eu tenho medo de colocar um marca-passo. A gente vê e escuta na televisão. Eu sei quenão tem cura. 0 marca-passo é uma cirurgia para melhorar, mas tem efeitosqueprejudicam. 0 caso do marca-passo pode ser um grande sucesso para pessoa, mas podetrazer grandes seqüelas também. Quer dizer, aí eu fico nervosa com aquilo. Porque além de eu ter tantos [problemas], que se eu não tivesse nada desses negócios e outros problemas. Se eu fosse uma muIher saudável, e só isso, eu não teria me incomodado de colocar um marca-passo. Eu sou alérgica, então tenho medo de tudo e de colocar um marcapasso. E de não me sentir melhor e piorar a minha vida. M as com o tempo eu fico nervosa. Eu estou com uma hérnia para operar, uma úlcera varicosa. 0 médico disse que quando a ferida fechar ele vai me operar. Eu tenho cada varize desse tamanho [mostrou as pernas direita e esquerda, e fez uma pausa]; 8) "Como você se sente com essa doença?" R: Eu me sinto muito triste. Choro muito. Estou desanimada. Não tenho vontade de falar, ver ninguém. Fico pensando que o meu coração está inchado, sinto mais coisas do que antes. Falta de ar, moleza, cansaço. M inha vida mudou. Bem, eu perguntei para o médico e ele disse que é preciso fazer exames, depende do caso e, no meu, pelo estado, vou ter que colocar um marca-passo. Eu sei dos efei tos do marca-passo na pessoa, émuito ruim ea cirurgia é complicada. A pessoa fica com o coração fraco [pausa com silêncio; choro por mais de um minuto. Estou abalada, não quero falar com ninguém. Fico sozinha pensando que posso morrer. Eu choro muito todos os dias e fico descontrolada. Choro até ficar sem ar. Não sei como tive forças para vir hoje. Foi a minha primeira consulta. 0 médico foi educado, metratou bem. Eleme confortou muito e explicou que tem tratamento. Ele me preparou. M as, eu saí daqui desesperada. Ele conversou comigo. Ele perguntou onde morei. Sei, morei em casa de barro. Se eu morei em casa de estuque ou sapê. Ele conversou muito. Elefoi muito bacana. Foi bacana demais, demais. Eu sei que esta doença não tem cura. Eu sei que vou morrer. Estou triste, minha vida mudou desde que recebi 0 resultado. Eu ouvi que a doença de Chagas não tem cura e sei que vou morrer. Minha família, irmãs e pais, morreram com problemas de coração lá em M inas Gerais. Eu tenho filhas e netas, mas cada um tem sua vida. Eu não posso nem quero atrapalhar. Q uando recebi o resultado, senti um aperto no peito e minhas pernas doem. Essa dificuldadee dor me causam muita tristeza, eu sinto o meu coração batendo forte. 0 doutor expli cou como éa doença eos exames, mas apesar deleser educado mesmo e me confortou muito, eu sei que vou morrer [fala direta por três minutos, seguida de silêncio por cerca de dois minutos; perguntamos se queria interromper a entrevista e ela respondeu: Não. Não; para recomeçar perguntamos se ela estava melhor]: Estou muito abalada dos nervos desde que recebi o resultado. Não quero morrer. Seguiu-se uma nova pausa para choro, por cerca deum minuto; perguntamos o que lhe passou pela cabeça quando soube do diagnóstico; Eu estou desesperada [pausa com silêncio]. M inha vida mudou muito, vivo triste e chorando, não quero me alimentar. Sei que vou morrer. Encadeamos a pergunta: "M udou algo na sua vida após o resultado dos exames?" e a resposta foi: M uito.U m desânimo tomou conta demim. Eu não tenho ami gos enão faço partede nenhum grupo de terceira idade.

As perguntas 9 e 10, sobre enfrentamento e tratamento - 9) "Qual é o principal problema que a senhora enfrenta com a doença de Chagas?"; 10) "Qual é o tipo de tratamento e/ou remédio que usa?"- foram respondidas em parte na fala da paciente às perguntas anteriores; por isso complementamos: 9) "O que você acha que vai lhe acontecer daqui para frente com essa doença?" R: Vou piorar atése conseguir fazer a cirurgia. Sei quenão tenho muito tempo mais pela frente; 10) "Você teme alguma preocupação por causa dessa doença?" R: N ão quero morrer.

A pergunta 11 , referente a seu acesso ao hospital -11) "A senhora tem alguma dificul dade para comparecer as consultas? Quais?" - foi adaptada: 11) "Como você foi recebida no hospital? Ocorreu al guma dificuldade? 0 quevocêespera do atendimento no hospital?" R: Eu não tive dificuldade para chegar, é que eu tenho o cartão do idoso. Não pago passagem. A única coisa que me incomodou é que estou com fome, cheguei muito cedo. M as trouxe um biscoitinho e bebi água. Estou fraca [interrupção para a paciente mostrar todos os exames que deverão ser realizados]. Eu estou tristee penso toda hora que vou morrer. Depois que recebi o re- 
sultado, naquele dia fui para casa com as pernas tremendo. Estou chocada e procuro não falar com ninguém, estou ficando isolada.

As perguntas 12 e 13, referentes aos serviços do hospital - 12) "A senhora conhece os serviços oferecidos no hospital para pacientes?"; 13) "A senhora tem dúvida sobrea sua doença? A quem procura no hospital para se informar mais?" foram feitas assim: 12) "A senhora conhece os outros serviços oferecidos pelo hospital?" R: Não. $\mathrm{N}$ ão conheço [ seguiu-se pausa com choro de cerca de um minuto]; 13) "A senhora gostaria de ser encaminhada para o serviço de psicologia?" R: Para que? Para fazer tratamento de nervos? [seguiu-se um esclarecimento da entrevistadora sobre os serviços de psicologia e o serviço social; perguntamos se tinha sido informada sobre sua existência]. R: Não. M as, as minhasirmãs em M inas, elas têm. Eu não sei [pausa com choro, por cerca de dois minutos]. Futuramente eu quero. Só que agora tenho que fazer os exames eu estou muito abalada. Quando tiver melhor. Eu só fico pensando que vou morrer. Isso não sai da minha cabeça o tempo todo.

A pergunta 14 , sobre tratamento, foi adaptada em virtude de ser a primeira consulta e ainda não ter sido prescrito tratamento. Perguntamos então se: 14) "A senhora depois que recebeu 0 resultado procurou algum tipo de ajuda? M édica, religiosa, grupo de amigos?" R: Não procurei. Eu não falo com ninguém. Nada vai adiantar. Eu não posso atrapal har a vida das minhasfilhas. Elas trabalham [falas sobre familiares]. E eu me sinto sozinha muito presa. Fico dentro de casa. Eu era assi m. Eu semprefui uma pessoa muito forte. Tudo eu fazia. Eu sempre fui uma pessoa muito forte. Sempre dei fortaleza para outra pessoa. Conforme eu estou hoje, agora eu não consigo. $N$ ão me sinto legal, sabe? Eu não sei o que está acontecendo comigo [a pesquisadora sugeriu o término da entrevista, mas a paciente insistiu em continuar]. Eu quero desabafar, fazendo um gesto indicativo de que estava com uma angústia no peito.

As duas últimas perguntas marcam a despedida da entrevista - 15) "A senhora gostaria de fazer alguma pergunta? Qual?"; 16) "A senhora gostaria de apresentar ou fazer al guma sugestão para melhorar 0 atendimento queé prestado aos pacientes?". O ptamos por não as fazer explicitamente; para encerrar a entrevista, agrademos a sua participação, reafirmando que essa participação será muito importante para o estudo e que certamente ela já ajudará que nosso trabaIho possa melhorar a qualidade do serviço. A paciente respondeu: Eu também gostei muito.
Quero o tel efone do serviço de psicologia. Depois eu ligo. Perguntamos: "Aonde a senhora vai agora?" Ela respondeu: Eu vou para Farmácia. Onde é? e decidimos acompanhá-la.

\section{Discussão}

0 teste do roteiro proposto nos permite tecer considerações sobre a natureza e a qualidade dos dados registrados en os leva a concluir que o instrumento está adequado para a coleta de dados sobre os saberes e percepções de pacientes chagásicos, e que poderá ser aplicado para subsidiar futuros trabalhos direcionados às práticas de pesquisa em serviço, numa abordagem de pesquisa qualitativa.

Sobreo perfil do paciente, captamos adequadamente os dados pessoais, com a reconstrução da sua trajetória no serviço de saúde. Ela havia sido atendida em outro hospital da rede pública, onde exames demonstraram insuficiência cardíaca e comprometimento do esôfago, suspeitando de doença de Chagas. Com essa suspeita diagnóstica que levou ao seu encaminhamento à Fiocruz, com o exame sorológico realizado há um mês, aguardando a confirmação de soropositividade para T. cruzi, a primeira consulta se reveste degrande expectativa quanto ao diagnóstico eao prognóstico da paciente. Chegou à Fiocruz por conhecer a instituição como referência para tratamento da doença de Chagas (eu já sabia que aqui se estuda muitas doenças e eu vim). M inas Gerais, onde a doença de Chagas foi descoberta, é um dos estados brasileiros com maior prevalência da doença ${ }^{48}$. Bom Despacho, a cidade onde nasceu a paciente, faz parte da Gerência Regional deSaúde deDivinópolis, região em fase de vigilância do controle, mas apesar disso os agentes desaúdequeatuam no controle afirmam que a população não reconhece facilmente os triatomíneos ${ }^{48}$.

Sobre as percepções e queixas, a entrevista detectou conceitos relativos à vida, saúde, direitos e o drama que é portar uma doença considerada incurável. Ela expressou livrementequal sentido esta doença representa em sua vida no momento. 0 roteiro obteve sucesso no objetivo de motivar a paciente a refletir sobre os aspectos sociais, históricos e culturais associados à sua doença, quando convidada a responder questões sobre sua história de vida. Sua fala revelou seu perfil socioeconômico e evidenciou um grande volume de queixas físicas (tenho pressão alta, dificuldade para engolir, fraqueza, hérnia, úlcera 
varicosa, osteoporose, artrose, eu sou toda complicada). Essa característica do paciente chagásico como "poli-queixoso" já foi detectada na experiência clínica do serviço de psicologia do IPEC e merece investigação mais detalhada.

Sobre os aspectos psicológicos, os dados evidenciaram al guns problemas tais como: tristeza, angústia, depressão e ansiedade, percebidas em relatos de sintomas como "vivo triste" (tristeza foi citada seis vezes na entrevista); " estou desespe rada, estou abalada" (angústia); "não tenho vontade de falar, ver ninguém, eu choro muito, todos os dias, choro até ficar sem ar (depressão); vou morrer, vou piorar até se conseguir fazer a cirurgia (ansiedadenegativa). Esses dadosindicam que 0 instrumento é adequado para captar aspectos psicológicos dos pacientes de modo a possibilitar um estudo aprofundado do componentepsíquico da doença de Chagas, que não podem ser abordados por exames clínicos ou complementares como os componentes cardiológicos e imunológicos da doença.

Sobre seus saberes, verificamos que a paciente dispunha de quatro saberes básicos sobre a sua doença ("eu sei"), muito arraigados e dos quaisfal ava com muita segurança: "o marca- passo é ruim e deixa seqüelas", "o coração incha", "a doença não tem cura", e que "vai morrer [dessa doença]". Todos estes saberes foram expressos com autonomia e grande carga emocional, decorrente do diagnóstico. Alguns desses saberes representam preconcepções equivocadas, como por exemplo, a idéia de morte, pois 70 a $80 \%$ dos pacientes infectados permanecem assintomáticos por toda a vida e morrem de outras causas ${ }^{11}$. Repetida espontaneamente doze vezes, essa certeza sobre o morrer pode ser fonte de grande ansiedade e angústia para a paciente. Pacientes submetidosa implante de marca-passo ${ }^{3}$ também apresentam essa idéia de que a doença de Chagas éa doença "quemata de repente", dissociando o saber cultural do paciente do saber científico, que comprova que a morte súbita ocorre apenas em $10 \%$ dos portadores da forma cardíaca, que por sua vez são apenas são $25 \%$ dos indivíduos infectados.

A ansiedade também pode surgir do saber sobre a cardiomegalia chagásica ("fico pensando que meu coração está inchado"), que naquela primeira consulta sequer estava confirmada. Saber que a "doença não tem cura", repetido sete vezes durante a entrevista, pode ter o mesmo efeito. Portanto, o roteiro de entrevista mostrou-se adequado para captar esses aspectos e, se um estudo quantitativo confirmar uma razoável freqüência desses saberes, poderá ser proposta uma intervenção de comunicação em campanhas informativas para minimizar um efeito negativo que eles possam causar nos muitos milhões de indivíduos infectados que, ao se saberem portadores do parasita, se autorotulam e são rotulados como portadores de doença de Chagas mesmo que estejam apenas infectados e não efetivamente doentes. $\mathrm{A}$ possível carga emocional desse diagnóstico já foi abordada na literatura ${ }^{2,3,13,22}$ e pode introduzir um componente simbólico importante que merece ser investigado com maior profundidade. Storino ${ }^{33}$ defende que sejam valorizados os aspectos psicossociais dos portadores da doença de Chagas, ressaltando que há uma grande diferença entre ser e estar doente, sendo o estado transitório ou permanente da doença fundamental na formação da identidade do indivíduo.

A través das perguntas abertas, o rotei ro permitiu que a paciente se libertasse de responder apenas às perguntas colocadas e passasse a discorrer com clareza sobre o que a doença estava significando na sua vida naquele momento. Ao mostrar a lista dos exames que teria que fazer e dos próximos passos a seguir, a senhora GMJS mudou da postura de "pacienteque espera 0 atendimento" para a "usuária dos serviços que Ihe foram apresentados e oferecidos". No entanto, apesar de seu conjunto de queixas, ela apresentou desinformação quanto a: (i) programas públicos de atenção básica, a exemplo do programa de hipertensão; (ii) seus direitos como usuária do SUS, pois não dispunha de cartão de atendimento; (iii) os serviços do IPEC ("não, não conheço"); (iv) seu direito a lanche no IPEC, pois comentou estar incomodada com a fome por ter chegado muito cedo para a consulta (quando não seria necessário, pois a consulta estava previamente agendada com horário marcado por sistema informatizado). 0 IPEC pode fornecer auxílio-alimentação e auxílio provisório para transporte a pacientes com doenças crônicas que não dispõem de cartão para isenção desse custo, mas na sua primeira consulta esses benefícios não Ihe ficaram esclarecidos.

A paciente expressou interesse em conhecer maiores informações sobre a doença de Chagas. Além disso, destacou a ausência de materiais para orientação sobre o tema e indicou a importância de entregar materiais informativos a outros pacientes no momento da consulta. Oliveira J $\mathrm{r}^{34}$ utiliza uma "Cartilha do portador de doença de Chagas" e outros materiais educativos. Com a aplicação do instrumento de pesquisa por nós produzido etestado, poderão ser investigados com maior 
profundidade os saberes, dúvidas e expectativas dos pacientes e um material apropriado poderá vir a ser desenvolvido, tal como proposto 6 .

A paciente associava o tipo de habitação com a infestação pelo barbeiro: casa deestuque ou sapê Por outro lado, também apresentava concepções distorcidas sobre o conceito de vetor e parasita. Constatamos ausência de informações espontâneas sobre as formas de transmissão da doença, com a paciente confundindo causa (infecção pelo parasita) e transmissão (vetor) com a mesma entidade: "o barbeiro". Este fato nos levou a refletir sobre a possi bilidade de associar ações educativas a momentos de presença dos pacientes nos serviços de saúde, de modo a aumentar sua educação em saúde e sua alfabetização científica.

Sobre as condições da real ização da entrevista, pelo fato de ter sido realizada em paciente de primeira consulta num local adjacente ao Serviço de Registro eProntuário médico, verificamos que 0 ideal seria a realização em sala reservada e específica para o acol himento dos pacientes chagásicos, a ser introduzida fisicamente de modo integrado ao percurso que o paciente deve fazer entre os diversos setores do hospital: consultório, prontuário, entrevista, farmácia, laboratório. Essa já será uma proposta de intervenção no serviço decorrente deste estudo.

Outro aspecto que merece discussão é a necessidade de aperfeiçoamento da linguagem do Termo de Consentimento (TCLE) no momento de apresentação da pesquisa e de sua assinatura. Quando da sua leitura, percebemos que o item "0 problema investigado", que se refere ao "objeto de estudo", foi entendido pela paciente como "o seu problema a ser investigado", pois ela estava defato enfrentando o "problema" de acabar de confirmar ser portadora de doença de Chagas e de ter sido encaminhada para "investigações" com exames complementares. Foi necessário esclarecer que aquilo se tratava do "tema a ser estudado"; 0 texto do TCLE deve ser alterado para facilitar a compreensão e o esclarecimento dos pacientes.

O grau de mobilização emocional da paciente também nos sugeriu que, para as demais entrevistas, seria bastante interessante contar com a presença deum profissional depsicologia. Apesar disso já estar previsto no projeto, a necessidade prática de deslocar fisicamente a paciente de um setor do hospital (consultórios no ambulatório) para outro (psicologia) não viabilizou a proposta eindicou a necessidade de um remanejamento de espaço adjacente ao consultório para que a entrevista pudesse transcorrer com maior conforto e tranqüilidade.

\section{Proposta de roteiro após o teste}

0 teste realizado com o roteiro de entrevista aprovado pelo CEP nos remete a dois aspectos que merecem ser discutidos: (1) as evidências de que a relação dialógica para a captação de dados com pacientes chagásicos precisa ser construída no contexto de uma pesquisa-ação, que associe coleta de dadose intervenção informativa eeducativa, necessárias frente ao conjunto de dúvidas e angústias expressas pelos pacientes; e (2) as evidências de que, apesar de adequado em diversos aspectos, o roteiro testado precisa de ajustes, especial mente quanto à linguagem da formulação das perguntas e ao seu ordenamento, situando a necessidade de maior flexibilidade do entrevistador quanto às perguntas, na condução do diálogo.

A proposta inicial de realizar uma pesquisaação, em que ao mesmo tempo da coleta de dados fosse possível realizar alguma intervenção educativa, foi bastante alterada pelas sugestões do Comitê de Ética em Pesquisa, restringindo as intervenções inicialmentepropostas ( 0 álbum de imagens fotográficas e o quadro de insetos). A emotividade deflagrada pelo processo de entrevista, expressa em diversos momentos de silêncio e em outros de choro da paciente, mostrou que são necessárias estratégias para suavizar esse sofrimento eque poderiam ser inseridos momentos no roteiro com os instrumentos inicialmente propostos. Por exemplo, o grandemedo da morte e a certeza de ser uma doença "que não tem cura" poderiam ser reduzidos com a apresentação das imagens de Berenice, a primei ra paciente em que Carlos Chagas descobriu a doença, e que viveu por décadas em fase indeterminada, vindo a falecer de outra causa não relacionada a essa infecção. Imagens desse tipo poderiam confrontar 0 preconceito da paciente de que "eu sei que vou morrer" e reforçar o conceito de que o indivíduo infectado pelo T. cruzi não necessariamentemorre do coração e nem de qualquer outro sintoma de doença e Chagas. Assim, apesar da expectativa aparente de que este roteiro de entrevista se concentrasse na subjetividade do paciente frente à doença, percebemos que real mente pode fazer sentido não o restringir apenas à col eta de depoimentos dos participantes. Trata-se de uma modificação de postura, pois o entrevistador poderá intervir sobre questões relevantes para a compreensão da patologia pelo paciente, bem como sobre seus saberes relativos a aspectos clínicos e epidemiológicos, quando for solicitado pelo paciente. 0 teste realizado nos indica que o roteiro efetivamente praticado estará adequado ao uso 
com um maior número de pacientes. 0 documento em anexo sistematiza o roteiro final que será aplicado.

0 que podem nos dizer as falas dos pacientes sobre a problemática social da doença Chagas e sobre as necessidades de mel horias no sistema público de atenção a essa população

$\mathrm{Na}$ fala da paciente captada no teste de nosso roteiro de entrevista, percebemos também uma lacuna na capacidade de articulação dos diversos serviços do hospital para que 0 atendimento possa integrar adequadamente os serviços mé dicos com todos os demais serviços complementares. Quando a paciente sai de uma consulta e nos diz não conhecer o serviço de psicologia, e nem a localização da Farmácia para onde devese dirigir em seguida, fica clara a necessidadede uma melhor sinalização visual no ambiente hospitalar e de um guia informativo sobre os serviços e benefícios disponíveis e sobre os procedimentos de registro e acompanhamento do paciente na coorte de doença de Chagas.

A pesquisa em serviço de saúde implica problemas éticos. Não se costuma discutir a questão da "violência simbólica" envolvida na relação entre o entrevistador e o entrevistado. M as um instrumento com perguntas controladas muitas vezes pode recair sobre o paciente como uma forma de violência. Ainda que possa ser argumentado que uma simples entrevista não tenha tal influência, por muitas vezes deixamos de admitir o fato de que precisamos nos colocar na posição de entrevistado ${ }^{46}$. 0 roteiro de entrevista apresentado poderá subsidiar uma melhor compreensão do perfil e subjetividade dos pacientes chagásicos num hospital de pesquisa clínica cuja característica de freqüência dos diferentes estágios evolutivos da doença ${ }^{49}$ é muito semelhante à distribuição da doença em área rural ${ }^{50}$. Portanto, acreditamos queo processo de estabelecimento de relações humanas com os pacientes concorre para desenvolver o sentimento de responsabilidade da equipe de saúde, bem como meIhorar os resultados e adesão ao tratamento, aumentando 0 grau de satisfação do paciente ${ }^{51}$.

\section{Conclusões}

0 instrumento de pesquisa se confirmou como adequado para o estudo de saberes de pacientes chagásicos, com captação de diversos aspectos subjetivos e cognitivos.

0 instrumento deverá ser ajustado em linguagem e ordenamento de questões para que a entrevista ocorra em forma de diálogo, propiciando a participação do paciente mais confortável.

Asfalas dos pacientes captadas com o instrumento proposto podem ser úteis para a formulação de estratégias, ações e materiais informativos que contribuam para a melhoria e humanização da atenção ao paciente chagásico.

A primeira consulta a pacientes chagásicos para confirmação de diagnóstico possivelmente pode se beneficiar da seqüência de atuação do médico e deum psicólogo, para suavizar o impacto das fortes emoções mobilizadas pelo diagnóstico.

\section{Colaboradores}

Todos os autores trabal haram igualmente na concepção do roteiro, na metodologia ena redação final do artigo. LM Ballester-Gil trabalhou na aplicação do roteiro e coleta de dados.

\section{Agradecimentos}

Agradecemos às psicólogas do IPEC, M árcia Franco da Silva e Tereza Cristina Amin, que contribuíram para a elaboração das idéias desse trabalho, ao Dr. Pedro Emmanuel Americano do Brasil pela realização das entrevistas com os pacientes. Estetrabal ho contou com o financiamento da Fundação Oswaldo Cruz/Instituto Oswaldo Cruz, do M inistério da Saúde/Departamento de Ciência e Tecnologia (Decit) e do Conselho Nacional de Desenvolvimento Científico e Tecnológico, em projetos aprovados sob a responsabilidade de Tania Cremonini de Araújo-Jorge. 
Anexo. Evolução do roteiro de entrevista para coleta de dados sobre saberes dos pacientes chagásicos sobre sua doença.

$$
\text { Primeiro roteiro de entrevista desenvolvido (4 blocos e } 50 \text { questões) }
$$

Bloco I. Acolhimento

a) Você poderia nos confirmar alguns dados? Nome, idade, endereço, naturalidade, tempo de residência no Rio de Janeiro, estado civil.

b) Você tem alguma outra dúvida? Quer perguntar alguma coisa?

c) Podemos prosseguir?

Bloco II: Coleta de dados

A. Perguntas sobre a sua saúde (aspecto emocional, com o objetivo de levantar dados sobre a reação do paciente ao diagnóstico e à evolução da doença).

A.1. Memória

1. Nos últimos tempos, como tem andado a sua saúde?

2. Quando e como você soube que estava com a doença de Chagas?

3. Como você se sente com essa doença?

4. Você conhece alguém com doença de Chagas (familiares, parentes, amigos, etc.) ?

5. Você sabe o que aconteceu com esta(s) pessoa(s) com doença de Chagas?

6. Opcional, caso tenha citado uma cirurgia: Você sabe que operação foi essa?

A.2. Reação

7. O que Ihe passou pela cabeça quando soube do diagnóstico?

8. Mudou algo na sua vida após o resultado dos exames?

A.3. Expectativas e temores

9. 0 que você acha que vai Ihe acontecer daqui para frente com essa doença?

10. Você teme alguma preocupação por causa dessa doença?

O pcionais, apenas para os que vão participar da pesquisa de algum ensaio clínico-terapêutico, uma vez que no IPEC alguns ensaios clínicos são realizados.

11. Qual a sua expectativa com relação a esse novo tratamento?

12. Como você foi recebido no hospital? O correu al guma dificuldade? 0 que você espera do atendimento no hospital?

13. Você acha que o sistema de saúde tem condição de lhe atender satisfatoriamente com relação a sua doença?

B. Queixas físicas do paciente (aspecto físico)

14. Você percebe algum sofrimento, desconforto ou dor física que se associe a essa doença?

Qual(is):

15. Você percebeu alguma mudança no seu corpo que você associe a essa doença?

16. Caso positivo, você percebeu algo específico quanto ao seu coração ou a sua barriga?

C. Percepções sociais do paciente com relação à sua doença (aspecto sociocultural)

17. Você já sofreu algum tipo de discriminação por causa dessa doença?

18. Essa doença Ihe causou algum prejuízo de trabalho ou de dinheiro?

D. Conhecimento do paciente sobre a sua doença (cognitivo)

19. Para você, o que significa estar doente?

20. 0 que você sabe sobre a doença de Chagas?

21. Você sabe por que a doença tem esse nome?

N esse momento, ocorrerá uma intervenção do entrevistador com a informação e as imagens históricas de Carlos Chagas, seus filhos e colaboradores, numa coleção de imagens em formato de álbum de fotografias (instrumento de intervenção 1).

22. Você sabe como adquiriu a doença?

23. Você sabe o que causa a doença de Chagas?

N esse momento, ocorrerá uma intervenção do entrevistador com a informação sobre o parasita, e com imagens do T. cruzi constantes no álbum (instrumento de intervenção 1).

24. Você sabe se algum tipo de animal pode transmitir a doença de Chagas?

N esse momento, ocorrerá uma intervenção do entrevistador com imagens sobre os triatomíneos vetores do $T$. cruzi (instrumento de intervenção 1 ).

25. Você associa alguma figura desse álbum como lugar favorável à transmissão da doença de Chagas? Qual?

N esse momento, ocorrerá uma intervenção do entrevistador com imagens sobre os casas e ambientes de risco propícios aos vetores do T. cruzi (instrumento de intervenção 1). 
26. Em relação à sua doença, você associa algum dos animais desse quadro à ela ?

N esse momento, ocorrerá uma intervenção do entrevistador com um quadro com os espécimes reais de triatomíneos vetores do T. cruzi, preparado em parceria com a Coleção Entomológica do Instituto Oswaldo Cruz (instrumento de intervenção 2)

27. Você mora ou morou em algum lugar onde percebesse 0 aparecimento de algum desses animais?

28. Você sabe como o causador da doença de Chagas entrou no seu corpo?

29. Você conhece outras maneiras pelas quais a doença de Chagas possa ser transmitida?

30. 0 médico lhe passou algum tratamento?

31. Você sabe como a doença de Chagas pode afetar o coração?

32. Você sabe qual o remédio indicado e para que ele serve?

33. 0 que espera desse tratamento?

Bloco III. Despedida

E. Conhecimento do paciente sobre os serviços do hospital

34. Você tem alguma dificuldade para chegar ao hospital?

35. Você conhece todos os serviços que podem ser prestados aos pacientes no hospital? Quais?

36. 0 que você achou do atendimento no hospital até agora?

37. 0 que você espera dos pesquisadores e da ciência brasileira com relação à sua doença?

38. Você acha que se deve pesquisar mais sobre essa doença? Por que?

39. Você gostaria de conhecer os resultados dessa pesquisa?

N esse momento, ocorrerá outra intervenção do entrevistador para registrar aquele momento de entrevista como algo especial para ambos, o paciente e o entrevistador. A "lembrança" a ser deixada será um cartão postal.

40. Nós vamos Ihe deixar uma lembrança dessa entrevista, sob forma de um objeto que você poderá guardar e também como convite para um encontro onde os pesquisadores estarão conversando sobre os resultados da pesquisa. Se você tiver alguma sugestão ou comentário a fazer, sinta-se à vontade.

41. Estamos pensando em montar um espaço para atividades para pacientes com doença de Chagas aqui no hospital? 0 que você acha dessa idéia?

42. Gostaria de falar mais al guma coisa sobre você ou sobre a sua doença?

Bloco IV. Confirmação de dados colhidos no prontuário

F. Perguntas sobre o perfil socioeconômico

43.Você trabalha atualmente?

44. Qual é a sua fonte de renda?

45. Sua renda familiar Ihe permite viver comodamente, com dificuldade ou sempre no vermelho? Gostaria de falar sobre isso?

46. Qual é o seu grau de estudo?

47. Quantos familiares convivem na mesma residência com você?

48. Dados habitacionais: $1=$ próprio; $2=$ alugado; $3=$ em vias de apropriação;

49.Tipo de periferia domiciliar: ( ) possui rede esgoto, ( ) água canalizada ( ) luz ( ) coleta de lixo; Tipo de habitação: c/ tijolos ( ) barraco ( ) ( ) Outros

50. Como você se alimenta no seu dia-a-dia? Que alimentos você usa com mais freqüência?

Quantas refeições você faz por dia?

Segundo roteiro, simplificado, aprovado pelo Comitê de Ética (2 blocos e 43 questões)

Bloco 1. Dados pessoais, perfil sócio-demográfico e econômico

Nome, idade, sexo, estado civil.

Naturalidade, nacionalidade,

Grau de instrução (alfabetizado, apenas assina o nome)

Possui filhos? Quantos?

Quantas pessoas convivem com a senhora (0)?

Qual é o seu endereço?

Sua casa é alugada, própria ou outra?

Em sua casa a água é encanada ou de poço? 
Tem rede de esgoto?

Tem coleta de lixo?

O (a)senhor (a) está morando no Rio de Janeiro há quanto tempo?

Qual é o lugar onde viveu nos últimos anos?

Em que trabalha atualmente (por conta própria, desempregado, outros)?

Qual é a sua renda mensal?

O (a) senhor (a) precisa de ajuda financeira de outra pessoa?

O (a) senhor (a) encontra dificuldades físicas para trabalhar? Por que? Caso positivo o que mais Ihe incomoda?

O (a) senhor (a) sabe se a pessoa com doença de Chagas recebe algum tipo de ben efício do governo?

O (a) senhor (a) recebe algum tipo de benefício da previdência social por estar com doença de Chagas?

Bloco 2. Percepções e saberes do paciente sobre sua doença e atendimento

1.Como o (a) senhor (a) ficou sabendo que é portador (a) da doença de Chagas?

2. De que forma conseguiu atendimento no IPEC?

3. 0 (a) senhor (a) lembra quem Ihe forneceu o resultado do exame? 0 que a pessoa disse na ocasião?

4.0 (a) senhor (a) recebeu algum tipo de informação sobre a sua doença durante as consultas?

5. Por que o (a) senhor (a) acha que adoeceu?

6. 0 que o (a) senhor (a) sabe sobre a sua doença?

7. Como está a sua saúde ultimamente? Sente alguma dor?

8. De que forma o (a) senhor (a) reage a esta doença?

9. Qual é o principal problema que o (a) senhor (a) enfrenta com a doença de Chagas?

10. Qual é o tipo de tratamento e/ou remédio que usa?

11.0 (a) senhor (a) tem alguma dificuldade para comparecer as consultas? Quais?

12.0 (a) senhor (a) conhece os serviços oferecidos no hospital para pacientes?

13. O (a) senhor (a) tem dúvida sobre a sua doença? A quem procura no hospital para se informar mais?

14. Já precisou de informaç̃ôes sobre o uso da medicação?

15.0 (a) senhor (a) gostaria de fazer alguma pergunta? Qual?

16. 0 (a) senhor (a) gostaria de apresentar ou fazer al guma sugestão para melhorar o atendimento que é prestado aos pacientes?

Terceiro roteiro, revisado, após o teste do roteiro simplificado (2 blocos e 27 questões)

Bloco 1. Dados pessoais, perfil sociodemográfico e econômico

Nome, idade, sexo, estado civil.

Naturalidade, nacionalidade,

Grau de instrução (alfabetizado, apenas assina o nome)

Possui filhos? Quantos?

Quantas pessoas moram com a senhora (0)?

Qual é o seu endereço?

Sua casa éalugada, própria ou outra?

Em sua casa a água é encanada ou de poço?

Tem rede de esgoto?

Tem coleta de lixo?

O (a)senhor (a) está morando no Rio de Janeiro há quanto tempo?

Qual é o lugar onde viveu nos últimos anos?

Em que trabalha atualmente (por conta própria, desempregado, outros)?

Qual é a sua renda mensal?

0 (a) senhor (a) precisa de ajuda financeira de outra pessoa?

O (a) senhor (a) encontra dificuldades físicas para trabalhar? Por que? Caso positivo o que mais Ihe incomoda? 
Bloco 2. Percepções e saberes do paciente sobre sua doença e atendimento

Como está a sua saúde ultimamente? (antiga pergunta 7 do roteiro testado, sem mencionar a palavra dor na pergunta)

Como você se sente com essa doença? (antiga pergunta 8 do roteiro testado, sobre reação, com modificação da linguagem)

(a: no caso de pacientes de primeira consulta) Qual foi o percurso, o encaminhamento, que o(a) trouxe para fazer essa consulta no hospital hoje? (nova pergunta, especial para pacientes de primeira consulta); (b: no caso de consulta de pacientes em acompanhamento)-Quando e como o (a) senhor (a) ficou sabendo que estava com a doença de Chagas ? Lembra quem Ihe forneceu 0 resultado do exame, quando e o que a pessoa disse na ocasião? (antigas perguntas 1 e 3 do roteiro testado)

O (a) senhor(a) recebeu algum tipo de material de informação sobre a sua doença aqui no hospital? (antiga pergunta 4 do roteiro testado, especificada quanto a material informativo e ao local de atendimento)

$O$ (a) senhor(a) sabe 0 que é doença de Chagas? (antiga pergunta 6 do roteiro testado, modificada) 0 que mais o(a) senhor(a) sabe sobre a doença de Chagas que lhe ajudasse a dar al guma informação sobre ela para outra pessoa? (em substituição à antiga pergunta 5 do roteiro).

Qual é o principal problema que o (a) senhor (a) enfrenta com a doença de Chagas, e o que acha que vai Ihe acontecer daqui em diante com essa doença? Tem alguma preocupação por causa dela? (antiga pergunta 9 do roteiro testado, complementada com abordagem sobre expectativa) Como o(a) senhor(a) foi recebido no hospital? Teve alguma dificuldade para comparecer à consulta? 0 que espera do atendimento? (antiga pergunta 11 do roteiro testado, complementada) $\mathrm{O}$ (a) senhor(a) conhece os outros serviços oferecidos no hospital para os pacientes? Conhece os benefícios a que pode ter direito quem tem essa doença? (fusão das antigas perguntas 12 e 13 do roteiro testado, associada à antiga pergunta do bloco 1 sobre benefícios)

(pergunta apenas para paciente em acompanhamento) Qual é o tipo de tratamento e/ou remédio que usa? Já precisou de informações sobre o uso da medicação? (antiga pergunta 14 do roteiro testado)

O (a) senhor (a) gostaria de fazer alguma pergunta ou de dar al guma sugestão para melhorar o atendimento que é prestado aos pacientes? (fusão das antigas perguntas 15 e 16 do roteiro testado)

\section{Referências}

1. Gomes $\mathrm{R}, \mathrm{M}$ endonça $\mathrm{EA}$, Pontes ML. As representações sociais e a experiência da doença. Cad Saúde Pública 2002; 18(5):1207-14.

2. Hueb MFD, Loureiro SR. Revisão: aspectos cognitivos e emocionais associados à doença de Chagas. Psicologia em Estudo 2005; 10(1):137-142.

3. Magnani C, Oliveira BG, Gontijo ED. Representações, mitos e comportamentos do paciente submetido ao implante de marca-passo na doença de Chagas. Cad Saúde Pública 2007; 23(7):1624-1632.

4. M inayo MCS. 0 desafio do conhecimento: pesquisa qualitativa em saúde. 8a ed. São Paulo: Hucitec; Rio de Janeiro: Abrasco; 2004.

5. Minayo MCS, Sanches O. O quantitativo-qualitativo: oposição ou complementaridade? Cad Saúde Pública 1993; 9(3):237-248.

6. Rozemberg B, Silva APP, Vasconcellos-Silva PR. Impressos hospitalares e a dinâmica de construção de seus sentidos: o ponto de vista dos profissionais de saúde. Cad Saúde Pública 2002; 18(6):1685-1694.

7. Morel CM. Neglected diseases: under-funded research and inadequate health interventions. EM BO Rep 2003; 4(Spec No):S35-S38.
8. Briceño-León R, M éndez-Galván J. The social determinants of Chagas disease and the transformations of Latin America. Mem Inst Oswaldo Cruz 2007; 102(Suppl I):109-112.

9. Dias JCP. Globalização, iniqüidade e doença de Chagas. Cad Saúde Pública 2007; 23(Supl 1):S13-S22.

10. World $\mathrm{H}$ ealth Organization. New global effort to eliminate Chagas disease. 2007. Available in: http:/ /www.who.int/mediacentre/news/releases/2007/ pr36/en/index.html

11. Prata A. Clinical and epidemiological aspects of Chagas disease. Lancet Infect Dis 2001; 1(2):92-100.

12. Gontijo ED, Rocha OMC, Oliveira UT. Perfil clínico-epidemiológico de chagásicos atendidos em ambulatório de referência e proposição de modelo de atenção ao chagásico na perspectiva do SUS. Rev Soc Bras M ed Trop 1996; 29(2):101-108.

13. Briceño-Leon R. Aspectos sociales, económicos, políticos, culturales y psicológicos. In: Storino R, Miles J, organizadores. Enfermedad de Chagas. Buenos Aires: Mosby Doyma; 1994. p. 534-41. 
14. Dias JCP. Doença de Chagas, ambiente, participação e Estado. Cad Saúde Pública 2001; 17(Supl):165-169.

15. Schall VT. Health education for children in the control of Schistosomiasis. M em Inst O swaldo Cruz 1987; 82 (Suppl 4):285-292.

16. Abalos JW. Health education and community participation in the eradication of Chaga's disease. Rev. Fac. Cienc. M éd. Córdoba, 1967; 25(3):279-283.

17. Petana WB. Educational approach in the control of Chagas' disease. Bull Pan Am Health Organ 1975; 9(4):300-305.

18. Esteso SC. Popular education: a fragile point in the campaign against Chagas' disease. Rev Fac Cien M ed Univ Nac Córdoba 1984; 42(2):14-17.

19. Vasconcellos EM. Popular education as a tool for redirecting strategies to deal with infectious and parasitic diseases. Cad Saúde Pública 1998, 14(Supl):39-57.

20. Diotaiuti L, Faria-Filho OF, Carneiro FC, Dias JCP, Pires $\mathrm{HH}$, Schofield CJ. Operational aspects of Triatoma brasiliensis control. Cad Saúde Pública 2000; 16 (Supl 2):61-67.

21. Dias JCP. Controle da doença de Chagas. In: Dias $J C P$, Coura JR, organizadores. Clínica e terapêutica da doença de Chagas, uma abordagem prática para o clínico geral. Rio de Janeiro: Fiocruz; 1997; p. 453-467.

22. Araújo SM, Cassarotti DJ, M ota DC, Borges SM, Gomes ML. The ACHEI Program: Chagas' disease awareness through comprehensive education in the municipality of M aringá, N orthwest Paraná, Brazil. Rev Soc Bras Med Trop 2000; 33(6):565-572.

23. Freitas HF, Nastari L, Mansur AJ. Dynamics of patients selection for heart transplantation or cardiomyoplasty. Arq Bras Cardiol 1994; 62(4):233-237.

24. Silva EF, Oliveira AL, Siefer MW, Gazetta ML, Bertani IF. Demographic profile and work situation of patients with Chagas disease. Arq Bras Cardiol 1995 65(1):43-46.

25. Petana WB. The importance of clinical, psychological and social effects experienced by patients with American trypanosomiasis (Chagas' disease). Bol Oficina Sanit Panam. 1980; 88(3):214-217.

26. Gwatirisa PR, N damba J, Nyazema NZ. The impact of health education on the knowledge, attitudes and practices of a rural community with regards to schistosomiasis control using a plant molluscicide, Phytolacca dodecandra. Cent Afr J M ed 1999; 45(4):94-97.

27. Chauí M. Cultura e democracia: o discurso compe tente e outras falas. $2^{\text {a }}$ ed. São Paulo: Editora M oderna; 1981

28. Smeke ELM, Oliveira NLS. Educação em Saúde e concepções de sujeito. In: Vasconcellos EM, organizador. A saúde nas palavras e nos gestos: reflexões da rede de educação popular e saúde. São Paulo: Hucitec; 2001. cap. 5.

29. Valla VV. Globalização e Saúde no Brasil: A busca da sobrevivência pelas classes populares via questão religiosa. In: Vasconcellos EM, organizador. A saúde nas palavras e nos gestos: reflexões da rede de educação popular e saúde. São Paulo: Hucitec; 2001

30. Uchôa E, Firmo JOA, Dias EC. Signos, significados e ações associadas à doença de Chagas. Cad Saúde Pública 2002; 18:71-79.

31. Carod-Artal FJ, Ribeiro LS, Vargas AP. Awareness of stroke risk in chagasic stroke patients. J Neurol Sci 2007; 263(1-2):35-39.
32. Bozelli CE, Araújo SM, Guilherme ALF, Gomes ML Perfil clínico-epidemiológico de pacientes com doença de Chagas no Hospital Universitário de $\mathrm{Ma}$ ringá, Paraná, Brasil. Cad Saúde Pública 2006; 22(5):1027-1034

33. Storino R. Aspecto psicológico. In: Storino R, Miles J, organizadores. Enfermedad de Chagas. Buenos Aires: M osby Doyma; 1994. p. 541-548.

34. Oliveira Jr W. Atenção integral ao paciente chagásico: uma proposta para o cuidar. Arq. Bras. Cardiol 2005; 84(1):1-2.

35. Stotz EN. Enfoques sobre Educação e Saúde. In: Valla VV, Stotz EM, organizadores. Participação popular, educação e saúde: teoria e prática. Petrópolis: Vozes; 1997. p:13-22

36. Freire P. Pedagogia da autonomia: saberes necessários à prática educativa. São Paulo: Paz e Terra; 1996.

37. Briceño-León R. Siete tesis sobre la educación sanitaria para la participación comunitaria. Cad Saúde Pública 1996; 12(1):7-30.

38. Kübler-Ross E. Sobre a morte e o morrer. São Paulo: M artins Fontes; 1981.

39. Valla VV. Participação popular e endemias: uma nova conjuntura. Cad Saúde Pública 1998; 14 (Suppl 2):7-18.

40. Valla VV, Stotz EM. Participação popular, educação e saúde: teoria e prática. Rio de Janeiro: Relume-Dumará; 1997.

41. Triviños ANS. Introdução à pesquisa em ciências sociais. São Paulo: Atlas; 1987.

42. Sanmartino M, Crocco L. Knowledge about Chagas disease and risk factors in Argentina communities with different epidemiological trends. Rev Pan Salud Publica 2000; 7:173-178

43. Bosi ML, Mercado FX. Pesquisa qualitativa de serviços de saúde. Petrópolis: Vozes; 2004.

44. Williams-Blangero S, Vandeberg JL, Teixeira AR. Attitudes towards Chagas' disease in an endemic Brazilian community. Cad Saúde Pública 1999; 15(1):7-13.

45. Queiroz MIP. Variaç̃oses sobre a técnica de informação viva. São Paulo: CERU e FFLCH/USP; 1983.

46. Bourdieu P. O poder simbólico. Rio de Janeiro: Bertrand Russel; 1998.

47. Ramognino N. Pour une approche dialectique en sociologie. Sociologie et Societés 1982; 14(1):83-95.

48. 48. Villela M M, Souza JM B, M elo VP, Dias JCP. Vigilância epidemiológica da doença de Chagas em programa descentralizado: avaliação de conhecimentos e práticas de agentes municipais em região endêmica de Minas Gerais, Brasil. Cad Saúde Pública 2007; 23(10):2428-2438.

49. Xavier SS, Sousa AS, Hasslocher-Moreno A. Aplicação da nova Classificação da Insuficiência Cardíaca (ACC/AHA) na Cardiopatia Chagásica Crônica: análise crítica das curvas de sobrevida. Rev SOCERJ 2005; 18(3):227-232.

50. Borges-Pereira J, Willcox HPF, Coura JR. Morbidade da doença de Chagas. III- Estudo Iongitudinal de seis anos em Virgem da Lapa, Brasil. M em Inst O swaldo Cruz 1985; 80(1):63-71.

51. Caprara A, Franco ALS. A relação paciente-médico: para uma humanização da prática médica. Cad Saúde Pública 1999; 15(3):647-654.

Aprovado em 16/01/2007

Versão final apresentada em 14/01/2007 